Marquette University

e-Publications@Marquette

$10-1-2016$

Evaluation of the Healing Progress of Pressure Ulcers Treated with Cathodal High-Voltage Monophasic Pulsed Current: Results of a Prospective, Double-blind, Randomized Clinical Trial

Anna Polak

Katowice School of Economics

Luther C. Kloth

Marquette University, luther.kloth@marquette.edu

Edward Blaszczak

Silesian Academy of Medicine in Katowice

Jakub Taradaj

Academy School of Physical Education in Katowice

Agnieszka Nawrat-Szoltysik

Physical Education Academy in Katowice

Accepted version. Advances in Skin \& Wound Care, Vol. 29, No. 10 (October 2016): 447-459. DOI. (C) 2016 Wolters Kluwer Health, Inc. Used with permission. 
See next page for additional authors 


\section{Authors}

Anna Polak, Luther C. Kloth, Edward Blaszczak, Jakub Taradaj, Agnieszka Nawrat-Szoltysik, Lidia Bialek, Malgorzata Paczula, Andrzej Franek, and Cezary Kucio 


\title{
Evaluation of the Healing Progress of Pressure Ulcers Treated with Cathodal High-Voltage Monophasic Pulsed Current: Results of a Prospective, Double-blind, Randomized Clinical Trial
}

\author{
Anna Polak \\ Department of Physical Therapy, \\ Academy of Physical Education in Katowice, \\ Medical Science Institute, Katowice School of Economics, \\ Katowice, Poland \\ Luther C. Kloth \\ Physical Therapy, Marquette University, \\ Milwaukee, WI \\ Edward Blaszczak \\ Department of Medical Biophysics, Medical University of Silesia, \\ Katowice, Poland \\ Jakub Taradaj \\ Department of Physical Therapy, Academy of Physical Education, \\ Institute of Physical Therapy, Public School of Medicine,


Opole, Poland.

\section{Agnieszka Nawrat-Szoltysik}

Department of Physical Therapy, Academy of Physical Education in Katowice, Sw. Elzbieta Caritas Skilled Nursing Facility,

Ruda Slaska, Poland.

\section{Anna Walczak}

Sw. Boromeusz Caritas Skilled Nursing Facility, Gliwice, Poland Lidia Bialek

Department of Medical Biophysics, Medical University of Silesia, Katowice, Poland

\section{Malgorzata Paczula}

Rehabilitation Center, Repty,

Tarnowskie Gory, Poland

\section{Andrzej Franek}

Department of Biophysics, Medical University of Silesia, Katowice, Poland

Cezary Kucio

Clinical Research Projects on Internal Diseases and Geriatrics, Physical Therapy, Academy of Physical Education in Katowice, Internal Medicine Department at the Specialist Hospital in Jaworzno, Poland.

\footnotetext{
Abstract

Objective: To investigate the effectiveness of high-voltage monophasic pulsed current (HVMPC) as an adjunct to a standard wound care for the treatment of Stage II and III pressure ulcers (PrUs).

Design: Prospective, randomized, double-blind, controlled clinical study.

Setting: Two nursing and care centers.

Patients: Patients with PrUs that did not respond to previous treatment for at least 4 weeks were randomly assigned to the electrical stimulation (ES) 
group ( 25 patients; mean age of $79.92 \pm 8.50$ years; mean wound surface area [WSA] of $10.58 \pm 10.57 \mathrm{~cm}^{2}$ ) or to the control group (24 patients; mean age of $76.33 \pm 12.74$ years; mean WSA of $9.71 \pm 6.70 \mathrm{~cm}^{2}$ ).

Interventions: Both the ES and control groups received standard wound care and respectively, cathodal HVMPC (154 microseconds; 100 pulses per second; $0.24 \mathrm{~A} ; 250 \mu / \mathrm{s}$ ) applied continuously for 50 minutes once a day, 5 times a week, or sham HVMPC.

Main Outcome: Percentage area reduction over 6 weeks of intervention.

Main Results: In the ES group, there was a statistically significant decrease in WSA after 1 week of treatment $(35 \% \pm 30.5 \%)$ compared with $17.07 \% \pm$ $34.13 \%$ in the control group $(P=.032)$. After treatment, at week 6 , percentage area reduction in the ES group was $80.31 \% \pm 29.02 \%$ versus $54.65 \% \pm 42.65 \%$ in the control group $(P=.046)$.

Conclusions: Cathodal HVMPC reduces the WSA of Stage II and III PrUs. The results are consistent with the results of other researchers who used HVMPC to treat PrUs.

Keywords: high-voltage monophasic pulsed current wound healing; pressure ulcers; electrical stimulation

\section{Introduction}

Pressure ulcers (PrUs) are a clinical problem for patients and medical personnel all over the world. The treatment of PrUs is, in most cases, a long process involving the application of various frequently costly interventions. It is therefore important to develop new methods that effectively promote and accelerate the healing of these intractable wounds. One of the methods used to treat PrUs is electrical stimulation (ES), which is recommended by the clinical practice guidelines as appropriate for treating chronic Stage II, III, and IV PrUs., 1,2

\section{The Evidence Supporting Electrical Stimulation for Wound Healing}

The authors of meta-analyses and reviews published in recent years point to the positive effect of ES on the healing of chronic wounds. $\frac{3-5}{-1}$ The systematic review of 174 studies (randomized trials and comparative observational studies) on different PrU treatment strategies in adults that Smith et al. $\frac{3}{}$ performed in 2013 showed moderately consistent results from 1 good-quality and 8 fair-quality trials, each of which presented ES as a biophysical energy capable of improving PrU healing rates. In the same year, Thalkral et al. 4 
reviewed 16 randomized clinical trials (RCTs) in which ES was used to treat wounds. They concluded that ES decreased bacterial infection, increased local perfusion, and accelerated wound healing. It is also noteworthy that none of the available studies mentions device-related complications or adverse effects of the electric field energy. In 2014, Koel and Houghton ${ }^{5}$ systematically analyzed 15 ES studies with clear randomized controlled design and published their findings of healing rate expressed as percentage area reduction (PAR) over 4 weeks of treatment. They concluded that applying additional monophasic ES to a program of standard wound care (SWC) increases the reduction of PrU area in 4 weeks of treatment by an extra $42.7 \%$ (95\% confidence interval, 32.0-53.3).

\section{Types Of Electrical Currents And Treatment Parameters}

The range of electric currents used in wound treatment research varies from low-intensity direct current 6,7 (LIDC; $<1.0 \mathrm{~mA}$ ), microamperage current $\frac{8-10}{2}$ (very low current imitating natural current of injury applied at subsensory level ${ }^{9}$ ), low-voltage biphasic pulsed current (LVBPC), 11-13 low-voltage monophasic pulsed current (LVMPC), 14-19 and high-voltage monophasic pulsed current (HVMPC). $\underline{20-27}$ In 2014, Houghton $\underline{28}$ published a systematic review of 32 clinical studies on LIDC, microamperage current, LVBPC, and LVMPC, and Polak et al. $\underline{29}$ performed a critical review of 11 clinical studies on chronic wounds treated with HVMPC. Both authors $\underline{28,29}$ reported that ES protocols involving the use of LVBPC, 28 LVMPC, 28 and HVMPC $\underline{29}$ were capable of producing consistently positive results in patients with chronic wounds. In the opinions of those authors, $\underline{28,29}$ the ES-induced improvement in wound healing depends on the type of ES waveform and the particular methodology used, but the optimal parameters of the stimulus and the ES schedule for chronic wounds still need to be defined.

In the RCTs, monophasic HVMPC was used to treat venous leg ulcers (VLUs), $\underline{22,24}$ PrUs, $\underline{20,21,25-27}$ and diabetic foot ulcers (DFUs). $\underline{23}$ In all of cited studies, HVMPC was applied for designated time periods with SWC (the latter intervention was necessary for ethical reasons). The results were compared with the effects of treatment in the control groups that respectively received only SWC $\frac{22,25-27}{2}$ or SWC and sham HVMPC. $20,21,23,24$ Authors of all cited studies indicated that HVMPC

Advances in Skin \& Wound Care, Vol 29, No. 10 (October 2016): pg. 447-459. DOI. This article is (C) Wolters Kluwer Health, Inc. and permission has been granted for this version to appear in e-Publications@Marquette. Wolters Kluwer Health, Inc. does not grant permission for this article to be further copied/distributed or hosted elsewhere without the express permission from Wolters Kluwer Health, Inc. 
promoted wound healing because the wound surface area (WSA) in the SWC + HVMPC groups decreased more than that in the control groups. $\underline{20-27}$

The parameters of HVMPC used in all cited studies were similar. The authors reported using twin-peak monophasic pulses $\underline{20-27}$ with a pulse duration of 100 microseconds $\underline{20,22-24,26,27}$ or 50 microseconds $\underline{25}$ and pulse frequency of typically 100 pulses per second (pps) 21,22,24-29 or 105 pps, $\underline{20}$ at which the current evoked only submotor sensory perception. ${ }^{20-27}$ Electrical stimulation involving HVMPC was usually applied for a total of 3.75 to 7 hours a week. $\underline{20-22,24,26,27}$ In most cases, treatment sessions of 45 to 60 minutes were held daily, 5 to 7 days a week. $\underline{20-22,24,26,27}$ Both electrodes were placed on a conductive saline, moist gauze, or on a wafer hydrogel dressing. The treatment electrode was placed on the wound surface, $20-27$ and the return electrode was attached to healthy skin at least 15 to $20 \mathrm{~cm}$ away. $\underline{20-}$ $\underline{22,24,26,27}$

The authors of the published studies used different treatment electrode polarities. In some cases, treatment started with cathodal stimulation that was continued over the whole length of the trial or was applied at the initial stage only. Griffin et al. $\underline{21}$ and Houghton et al. $\underline{24}$ had good results treating PrUs 21 and VLUs $\underline{24}$ using only the cathode. In the first of the 2 studies, $\underline{21}$ Stage II through IV PrUs in the ES group (SWC + ES) demonstrated significantly greater percentageof-change decrease in WSA from their pretreatment size than did ulcers in the control group (SWC + sham ES) at days 5, 15, and 20 (P $<.05) \cdot \underline{21}$

In the second study, ${ }^{24}$ by week 4, WSA in the ES group (SWC + ES) decreased by $44.3 \%$ compared with only $16 \%$ in the control group ( SWC + sham ES) with $\mathrm{P}<.05$. In another study conducted by Houghton et al, $\underline{25}$ PrUs (mostly Stage III and IV) were stimulated with the cathode in the first week, and then polarity was reversed every week until the end of the 12-week treatment period. Percentage area reduction of PrUs was evaluated at weeks 1, 2, and 3. There was significantly less WSA from baseline in the ES group (SWC + ES) than in the control group (SWC alone) at month $3(P=.048)$. Franek et al. $\underline{22,26}$ and Polak et al. $\underline{27}$ too, started the treatment of VLUs $\underline{22}$ and PrUs $\frac{26,27}{}$ with cathodal stimulation that was continued for the first 1 to 3 weeks depending on the growth of granulation tissue. When at least 
$50 \%$ of the wound surface was covered with granulation tissue, the anode was introduced as the treatment electrode until the end of treatment that lasted 6 weeks $\underline{22,26}$ and 4 weeks, $\underline{27}$ respectively. The authors of the first study $\underline{22}$ reported that after 2 weeks of cathodal stimulation the granulation tissue area in VLUs was significantly greater $(P<.003)$ in the ES group (SWC + ES) than in the control group (SWC alone) and that 6 weeks of treatment decreased the area of VLUs more in the ES group (the decrease was not significant, $\mathrm{P}$ $>$.05) than in the control group. $\underline{22}$ The results obtained by the authors of the second study $\underline{26}$ involving Stage II and III PrUs were slightly different. The ES group (SWC + ES) and the control group (SWC alone) were similar in the area of granulation tissue over the whole period of treatment $(P>.05)$, but after 6 weeks of treatment, PAR in the ES group was greater than that in the control group ( $P$ $=.00003) . \underline{26}$ The authors of the third study $\underline{27}$ (a preliminary trial with a sample of only 22 patients with Stage II and III PrUs) recorded that percentage decrease in PrU area after 4 weeks of treatment was significantly greater in the ES group (SWC + ES) than that in the control group (SWC alone) with $\mathrm{P}=.0079$ (they did not record the area of granulation tissue). The methodology that Kloth and Feedar $\underline{20}$ followed to apply cathode and anode as the treatment electrodes was considerably different from the methodologies used in the presented studies. They stimulated Stage IV PrUs with the anode and reversed polarity to negative only if healing progress was not satisfactory. In the ES group ( SWC + ES), WSA decreased at a mean rate of $44.8 \%$ a week and closed $100 \%$ over a mean period of 7.3 weeks. In the control group (SWC + sham ES), WSA decreased by an average of $28.9 \%$ over an average period of 7.4 weeks. The different polarity of the treatment electrode used in the studies and slightly different results obtained by their authors suggest that more clinical research is needed to determine the wound healing efficacy of the cathode and the anode.

Some progress has been made toward the creation of more reliable guidelines on the use of the 2 electrodes in treating wounds in humans. Having reviewed the results of in vitro and in vivo studies, Kloth and Zhao $\underline{30}$ have concluded that both these electrodes promote wound healing and that the polarity of the treatment electrode should enhance the cellular needs during the inflammatory and proliferative phases of healing. 
The authors of in vitro studies 31,32 have reported that anodal stimulation facilitates electrotaxis of macrophages ${ }^{31}$ and neutrophilis ${ }^{32}$ for autolysis and reactivation of the inflammatory phase of healing. Eberhardt et al. $\underline{33}$ have demonstrated in vivo electrotaxis of neutrophils toward the anode. The efficacy of anodal stimulation in the early stages of wound healing has been recently confirmed from in vivo studies with animals. $\frac{34,35}{}$ Talebi et al. ${ }^{34}$ studied in vivo the effect of anodal and cathodal ES $(600 \mu \mathrm{A} ; 1$ hour per day; 3 sessions a week for a period of 3 weeks) on injury potential and wound size in guinea pigs. They concluded 34 that anodal ES was appropriate as a means of improving the healing of acute skin wounds, because it causes the wound surface to close and decreases healing time. The Borba et al. $\frac{35}{}$ randomized in vivo study with rats showed that anodal stimulation (rectangular pulse current of $8 \mathrm{~mA}$ at a frequency of 7.7 pps) improved neoangiogenesis in the early stage of acute experimental wound healing.

Cathodal ES has been found to enhance the proliferative phase of wound healing. In vitro studies $\frac{36-39}{2}$ have demonstrated that in cell cultures, human fibroblasts,, $36-38$ keratinocytes,, 36 and bovine corneal epithelial cells ${ }^{39}$ migrate directionally toward the cathode. The studies imply that cathodal stimulation promotes granulation tissue formation. $\frac{36,38,40,41}{1}$ The results of Bourguignon and Bourguignon's $s^{41}$ in vitro study with human fibroblasts indicated that HVMPC (twin-spike pulses; 100 microseconds; 100 pps) could significantly increase the rate of protein and deoxyribonucleic acid synthesis. They observed that maximum synthesis of protein and deoxyribonucleic acid occurred at 50 and $75 \mathrm{~V}$ in cells located adjacent to the negative electrode. According to Zhao et al. $\frac{39}{\text { the negative electrode can }}$ effectively stimulate the epithelialization of wounds.

Asadi et al. $\underline{42}$ found from in vivo research that cathodal sensorylevel ES increases the release of vascular endothelial growth factor (VEGF) in skin. Their study was designed to evaluate the effect of sensory (LIDC; $600 \mu \mathrm{A}$ ) and motor (monophasic current; pulse duration 300 microseconds, 100 pps, 2.5-3.0 mA) cathodal ES on VEGF release in muscle and skin in the wound site in 48 male Sprague-Dawley rats randomly assigned to 2 experimental groups and a control group (ES was not applied). A full-thickness skin incision was made on each animal's dorsal region. The experimental groups 
received ES for 1 hour for 3 or 7 days. The VEGF expression in muscle and skin was measured on days 3 and 7 after surgical incision. On day 3, VEGF levels did not differ among the groups. On day 7 , the periwound cutaneous VEGF levels were significantly higher in the sensory-level stimulation group than in the other groups $(P<.05)$. No differences in VEGF were found in muscle tissue. These results led Asadi et al. $\underline{42}$ to conclude that the sensory-level cathodal ES increases the release of VEGF in skin. This may explain why a negative current applied at a sensory level can effectively promote the proliferative phase of wound healing. In the clinical study by Franek et al. $\underline{22}$ cathodal HVMPC (100 microseconds; 100 pps) was observed to improve granulation tissue growth in VLUs. After 2 weeks of treatment, the area of granulation tissue in the group receiving SWC with compression therapy plus cathodal HVMPC was significantly greater than in the control group where only compression therapy and SWC were applied $(P<.003)$.

The authors of the reviews of clinical studies $\frac{5,43}{}$ and of epidemiological studies $\underline{44}$ point to wound closure as the most important endpoint in evaluating the efficacy of wound treatment, but in clinical studies with ES, treatment is rarely continued until wounds close completely (in only 1 of the reviewed clinical studies were all PrUs treated with HVMPC until full closure ${ }^{20}$ ), so the percentages of wounds that closed after 4, 6, or 12 weeks of treatment are frequently reported instead. In trials that end before wounds are closed, the PAR of wounds after treatment in relation to baseline is crucial, $\underline{5,43,44}$ so in the majority of the reviewed studies, the wound healing progress is expressed as PAR. $\underline{20-27}$ Gilman $\underline{45,46}$ has put forward a formula (Gilman formula [GF]) for calculating the healing rate for wounds of all shapes.

\section{Aim Of Study}

The aim of this clinical study was to establish whether a cathodal HVMPC could improve the healing of chronic PrUs in older adults with Stage II and III PrUs.

Based on research findings previously cited, the authors formulated the following research hypothesis: that cathodal HVMPC is capable of decreasing PrU surface area regardless of the wound shape and can significantly accelerate the healing process. 
NOT THE PUBLISHED VERSION; this is the author's final, peer-reviewed manuscript. The published version may be accessed by following the link in the citation at the bottom of the page.

\section{Methods}

A prospective, randomized, double-blind clinical trial was conducted with 2 groups of patients to compare the healing of PrUs after 6 weeks of intervention involving SWC combined with cathodal ES, as well as SWC with sham ES. Ethics approval for the experiment was granted from the Academy of Physical Education in Katowice Bioethics Commission. The study was registered in Australian New Zealand Clinical Trials Registry (ANZCTR12614000207617).

\section{Participants}

\section{Eligibility}

Patients screened for the trial were hospitalized in 2 nursing and care centers. The patient's eligibility to participate in the study was assessed by their physician based on the following criteria: older than 60 years, at high risk of PrU development ( $<14$ points on the Norton scale), with a PrU of between 1.0 and $50 \mathrm{~cm}^{2}$ and duration from 1 to 12 months. In order to make the comparable groups as analogous as possible, only individuals with Stage II and III PrUs (which are typically diagnosed in older adult patients) located on the pelvic girdle (sacrum, coccyx, ischial tuberosity, trochanter major) were included in the study.

The patients who did not qualify for ES (contraindications include cancer, electronic implants; malignant, tunneling, and necrotic wounds; osteomyelitis; PrU requiring surgical intervention; and metal implants in the PrU area) were excluded from participating, as well as those with diagnoses that might interfere with wound healing, such as diabetes $\left(\mathrm{HbA}_{1 \mathrm{c}}>7 \%\right)$, venous insufficiency, critical infection, alcoholism, and allergy to standard wound treatment.

\section{Demographic Information}

Patient demographics were obtained from standard interviews, physical examinations, and the history of concomitant diseases contained in the patients' medical records. Before the study began, the Norton scale was used to assess the patients' physical and mental condition, the level of activity, mobility, and incontinence; with the Braden scale, the risk of friction and shear, wound moisture, sensory perception, physical activity, and mobility were determined. A comprehensive review of the patients' nutrition was also conducted,

Advances in Skin \& Wound Care, Vol 29, No. 10 (October 2016): pg. 447-459. DOI. This article is (c) Wolters Kluwer Health, Inc. and permission has been granted for this version to appear in e-Publications@Marquette. Wolters Kluwer Health, Inc. does not grant permission for this article to be further copied/distributed or hosted elsewhere without the express permission from Wolters Kluwer Health, Inc. 
including the assessment of factors that might influence dietary intake and of the extent of nutrient and fluid losses. The nutritional status of a patient was quantified by means of the Nutritional Risk Score (NRS 2002). $\frac{47}{}$

\section{Wound Severity}

Wound severity at enrollment was established by the physician using the National Pressure Ulcer Advisory Panel ${ }^{1}$ criteria (with Stage II PrUs meaning partial-thickness loss of the dermis presenting as a shallow open ulcer with a red-pink wound bed, no slough; and Stage III PrUs meaning full-thickness tissue loss, subcutaneous fat may be visible, but the bone, tendon, or muscle is not exposed).

\section{Interventions}

\section{Wound Care Program Administered To Both Groups}

Pressure ulcer prevention measures, wound care, and physical treatment were administered to all patients using the same prospective protocol and under the supervision of the main investigator. Each patient was comprehensively assessed by an interdisciplinary medical team to develop an individualized wound prevention and treatment program consistent with best practices. $\frac{1,2,48}{}$ The physicians assessed the general condition of the patients and their PrUs, as well as developing treatment programs. When necessary, neurologists, cardiologists, diabetes specialists, surgeons, and other specialists were also consulted. The nurses gave care to the patients, administered drugs, and applied dressings to wounds as prescribed by the physicians. The physiotherapists created and implemented kinesiotherapy programs for the patients. The physiotherapists, nurses, and clinical caregivers were responsible for applying measures to prevent the development of PrUs, including the repositioning of the patients. The dietitians assessed the nutritional status of the patients and developed therapies to make up for nutritional deficiencies. The clinician caregivers were blinded to study group assignments.

All patients received treatment to prevent the development of additional PrUs. Pressure-redistribution surfaces, devices, and pillows were provided as needed. Persons who could change position were asked to do so as often as possible to relieve pressure on the ulcer area. At least once every 2 hours, a nurse, physiotherapist, or clinical 
caregiver determined whether the patients had changed position. The patients who could not move on their own were repositioned by a nurse or physiotherapist.

Blood analysis was performed to screen for nutritional status markers and metabolic disorders such as anemia (iron deficiency anemia or anemia of chronic disease), thyroid dysfunction, impaired glycemic control, dehydration, protein deficit, and hypoalbuminemia.

The attending physician regularly examined patients' wounds to determine what topical treatments were needed. Intervention included tissue debridement, infection and inflammation control, maintaining moisture balance, and the monitoring of wound edges and the process of epithelialization. Wounds were cleaned with antiseptics and then covered with hydrogel or hydrocolloid dressings to trigger autolysis. Necrotic tissue was cleaned enzymatically, and infected wounds were rinsed with antiseptics. When bacterial infection was suspected (presence of fever, leukocytosis, high level of Creactive protein, and/or redness and inflammatory infiltration around the wound) patients were administered antibiotics. Wounds were treated with topical dressings appropriate for the stage of wound healing, the depth of the wound, the presence of infection, and the presence of exudates, and wound intensity. Cleaned wounds with granulation tissue and moderate exudate were covered with dressings moistened with $0.9 \%$ sodium chloride, hydrocolloid, or polyurethane foam dressings. Wounds showing necrotic tissue and wounds with considerable exudate were covered with hydrogel dressings or alginate dressings. All immobilized patients received low-molecularweight heparin as a standard therapy.

\section{Electrical Stimulation}

In addition to SWC, patients in the ES group and in the control group both received active HVMPC and sham HVMPC.

The HVMPC device was the Intelect Advanced Combo unit (model 2771 by Chattanooga Group, Vista, California), which was set to generate a twin-peak monophasic pulse (154 microseconds) consisting of two 77-microsecond exponential pulses in rapid succession. The pulse frequency was 100 pps, and the peak electric current was usually 0.24 amperes (A), so it induced only sensory perception in the patients without any motor reactions. The voltage 
was set to $100 \mathrm{~V}$, and the charge delivered by the electrodes was 250 microcoulombs $(\mu \mathrm{C})$ per second. This protocol was adopted because of the positive results of earlier clinical trials on patients with PrUs $\underline{20,21,26,27}$ and VLUs. $\underline{22,24}$ The patients participated in 5 sessions of 50 minutes in length per week (Monday through Friday) according to the protocols used in other studies. $\underline{20-22,26,27}$

All patients were treated in the same way using identical stimulators that had 2 independent circuits for delivering electrical current; according to the study protocol, only 1 circuit was active. The electrical current parameters (pulse duration and shape, frequency, and voltage) and the duration of the procedure were displayed on the monitor so that patients in both groups could see them, but in the control group, the electrodes were connected to the inactive electrical circuit. The person in charge of connecting the electrodes to the appropriate circuit (active or passive) was the facility chief physiotherapist, who did so in an inconspicuous manner to prevent the patient, the physiotherapist in charge of the procedure, and other members of the medical team (physicians, nurses, caregivers) from knowing whether real or sham ES was applied.

Each patient was provided with his/her own set of conductive carbon-rubber electrodes. The treatment electrode $(5.0 \times 10.0 \mathrm{~cm})$ was placed on an aseptic gauze pad saturated with physiological saline overlying the wound site. The return electrode $(10.0 \times 10.0$ $\mathrm{cm}$ ) closing the electrical circuit was placed on a gauze pad saturated with physiological saline and applied to healthy skin at least $20 \mathrm{~cm}$ from the PrU.

Pressure ulcers were stimulated with the cathode during each daily treatment period, as in the clinical studies on PrUs $\underline{21}$ and VLUs. $\underline{24}$ The preclinical studies $\frac{36-40}{}$ have shown that the cathode can enhance fibroblast and epithelial cell motility and stimulate granulation tissue growth and reepithelialization.

Before and after each procedure, the electrodes were sterilized in disinfectant solutions (Incidin Liquid and Sani-Cloth Active; Ecolab, Monham am Rhein, Germany). The PrUs were thoroughly cleansed with a $0.9 \%$ sodium chloride solution and covered with the aforementioned dressings as soon as the procedure was complete.

In both groups, the healing of PrUs was monitored for 6 weeks or until wounds closed, whichever occurred first. This specific length 
of observation was imposed by the duration of patient stay in nursing and care centers ( 6 weeks on average).

In patients with more than 1 PrU, all wounds were treated, but only the most severe wound was analyzed statistically.

\section{Outcomes}

\section{Primary Outcome}

The primary outcome in both groups was percentage reduction in WSA in relation to the baseline at week 4 (PAR4) and at week 6 (PAR6) enabling the comparison of wound healing progress between the groups.

\section{Secondary Outcomes}

The secondary outcomes were as follows:

1. the value of GF $\underline{45,46}$ for comparing wound healing progress regardless of wound shape;

2 . average percentage change in wound area by weeks 1 through 6 of treatment (PAR/week 1, PAR/week 2, PAR/week 3, PAR/week 4, PAR/week 5, PAR/week 6), calculated to determine in which week WSA decreased the most; and

3. percentages of PrUs in which WSA closed or increased (relative to the baseline), which were calculated after 6 weeks of intervention.

\section{Sample Size}

Group sizes appropriate for the study were established through a pilot study. Because results were obtained from the random pilot, the sample had unimodal distribution with skewness and flatness below 2.5. Thus, the arithmetic average and standard deviation (SD) were accepted as reliable measures of central value and dispersion. Based on type I error, probability [alpha] $=.05$ and test power 1 [beta] $=.90$ were selected. An assumption was made that for wound healing progress to be statistically significant the improvement against the baseline must be at least $20 \%$ in both groups. The groups were initially assumed to consist of at least 48 randomly selected patients (24 in a group), but to allow for dropouts, 60 participants were finally selected. 
NOT THE PUBLISHED VERSION; this is the author's final, peer-reviewed manuscript. The published version may be accessed by following the link in the citation at the bottom of the page.

\section{Randomization/Blinding}

After the included patients, or their legal guardians as appropriate, granted their written consents to participate in the study, they were randomly allocated between the ES group (SWC plus active HVMPC) and the control group (SWC plus sham HVMPC) using a concealed process (Figure 1). The allocation procedure did not consider who was to receive and when to deliver the treatment.

The randomization schedules were constructed with blocks of 2 to ensure equal distribution of patients across the 2 groups. The allocation sequence was concealed by using sealed envelopes with consecutive numbers. After baseline measurements of the patients, the main investigator opened the envelopes one at a time in the presence of the principal physiotherapist, and the particular patient was directed to the indicated group.

All patients, physicians, care providers, and physiotherapists, as well as the person making weekly measurements of WSA and the statistician processing the data, were blinded. The only person engaged in the experiment who was not blinded was the principal physiotherapist, who set the devices to apply active or sham ES.

\section{Measures and Statistical Methods}

Before the study commenced and at the end of each week of treatment, 7 measurements were taken to establish each patient's WSA (in $\mathrm{cm}^{2}$ ). For all PrUs that closed before the end of week 6, the date of closure was recorded. A wound was defined as closed when its surface area decreased to $0 \mathrm{~cm}^{2}$.

The WSA for all patients was measured by a blinded person who used the same method as that used in several other clinical trials. $\frac{22,26,27}{}$ After the contours of wounds were transferred onto transparent film, they were measured with the planimeter to establish the WSA. The data obtained were processed by a digitizer (Mutoh Kurta XGT; Altek, Liberty Lake, Washington) connected to a personal computer (C-GEO version 4.0; Instrumenty Geodezyjne Thadeusz Nadowski, Tychy, Poland), which was also used for storing the results.

Measurement errors arising from different wound shapes ranged between $2.7 \%$ (for PrUs of $60-70 \mathrm{~cm}^{2}$ ) and $37.9 \%$ (PrUs $<1$ $\mathrm{cm}^{2}$ ). The errors were calculated with the following formula: [DELTA]S / $\mathrm{S}=\mathrm{I} \times[\mathrm{DELTA}] \mathrm{r} / \mathrm{S}$, where $[\mathrm{DELTA}] \mathrm{S} / \mathrm{S}$ is the relative error of the 
wound area measurement method; [DELTA]S is the absolute error of area measurement; $\mathrm{I}$ is a wound perimeter; [DELTA]r is the absolute error related to the thickness of the plotting pen $(0.2 \mathrm{~mm})$ and to the digitizer's cross-hair $(0.1 \mathrm{~mm}) ; \mathrm{r}=2 \times 0.2 \mathrm{~mm}+0.1 \mathrm{~mm}$. A detailed discussion of the method used to calculate measurement errors is provided in the authors' earlier study. $\underline{26}$

Both PAR4 and PAR6 were calculated in the following way:

The GF was:

The percentage change in wound area at weeks 1 through 6 were calculated as follows:

The statistical analysis was performed by a blinded person using the Statistica software (version 10.0; StatSoft Polska Sp. z 0.o, Krakow, Poland). Patient characteristics were checked for normal distribution using the Shapiro-Wilk W test. When the distributions were found not to be normal, nonparametric tests were applied to evaluate the results of the study. The distributions of patient characteristics were tested for skewness, kurtosis, and modality. Because skewness and kurtosis were in all cases smaller than 4, and the distributions were unimodal, a mean and an SD were used to measure the central value and dispersion.

Both comparative groups were tested for the homogeneity of patient characteristics using the 2-sided Fisher exact test and the Mann-Whitney $U$ test. The Mann-Whitney $U$ test was also used to compare mean percentage change in WSA and the values of GF between the groups and to establish the statistical significance of differences in weekly healing rates between the groups. The percentages of PrUs that closed or increased in size were compared between the groups after 6 weeks of treatment using the 2-sided Fisher exact test. In all cases, the level of significance was set at $P$ $<.05$.

\section{Results}

\section{Participant Flow}

Between November 1, 2013, and December 30, 2014, 72 patients were screened for participation in the study. Twelve of those patients were not randomized to receive treatment, and 11 of the 
NOT THE PUBLISHED VERSION; this is the author's final, peer-reviewed manuscript. The published version may be accessed by following the link in the citation at the bottom of the page.

remaining 60 patients (18.33\%) dropped out before the end of the 6 week treatment period (Figure 1).

\section{Baseline Data}

Tables 1 and $\underline{2}$ contain the demographic and wound characteristics of 49 patients in 2 groups who completed the study. There were no statistically significant differences between the groups regarding any variable measured at the baseline.

The patients were treated in 2 nursing and care centers that strived to prevent the development of PrUs and treated the wounds according to the same standards. The sample of patients consisted of 37 women (75.51\%) and 12 men (24.49\%) ranging in age from 60 to 95 years, but mostly older than 80 years $(n=27 ; 55.1 \%)$. All patients scored on the Norton scale below 14 points. Thirty-nine patients (79.59\%) were immobile, or their mobility was very limited. Thirty-four patients (69.39\%) received a diagnosis of generalized atherosclerosis, 19 (38.77\%) had type 2 diabetes $\left(\mathrm{HbA}_{1 \mathrm{c}}<7 \%\right)$, and $19(38.77 \%)$ were affected by a cerebral stroke.

The patients had a total of 49 PrUs that ranged in size from 1.18 to $38.34 \mathrm{~cm}^{2} ; 22$ PrUs were Stage II (44.9\%), and 27 were Stage III (55.1\%). Of the 49 PrUs, 25 (51.02\%) were located in the sacral region, 17 (34.69\%) on the ischial tuberosity, and 7 (14.28\%) on the trochanter. Eleven patients (22.45\%) had multiple PrUs, and in 23 patients (46.94\%), recurring PrUs were diagnosed. The duration of the PrUs before the clinical trial began was 1 to 12 months, with most lasting 1 to 3 months ( $\mathrm{n}=37 ; 75.51 \%)$.

\section{ES Group}

The ES group consisted of 25 patients, 19 women and 6 men, at a mean age of 79.92 years (range, 60-92 years). Two patients $(8 \%)$ were obese (body mass index $[\mathrm{BMI}],>30 \mathrm{~kg} / \mathrm{m}^{2}$ ), and $4(16 \%)$ were underweight (BMI $\left.<19 \mathrm{~kg} / \mathrm{m}^{2}\right)$. Twenty patients $(80 \%)$ could not change position unless assisted. Sixteen patients $(64 \%)$ had general atherosclerosis, 11 (44\%) had diabetes $\left(\mathrm{HbA}_{1 \mathrm{c}}<7 \%\right)$, and 9 (36\%) were affected by cerebral strokes. This group was diagnosed with a total of 25 PrUs, of which 13 (52\%) developed in the sacral region, 8 $(32 \%)$ on the ischial tuberosity, and $4(16 \%)$ on the trochanter. Fourteen PrUs (56\%) were Stage III, and 11 (44\%) were Stage II. Their average duration was 2 months (range, 1-10 months), but most 
of them ( $n=19 ; 76 \%$ ) developed less than 3 months before the study began. Six patients (24\%) had more than 1 PrU, the largest of which was monitored for healing.

\section{Control Group}

The control group consisted of 24 patients, 18 women and 6 men, at a mean age of 76.33 years (the range was 60-95 years). Three patients $(12.5 \%)$ were obese (BMI $\left.>30 \mathrm{~kg} / \mathrm{m}^{2}\right)$, and $2(8.33 \%)$ were underweight $\left(B M I<19 \mathrm{~kg} / \mathrm{m}^{2}\right)$. Twenty patients $(80 \%)$ needed assistance to change position. Eighteen patients (75\%) had general atherosclerosis, $8(33.33 \%)$ had diabetes $\left(\mathrm{HbA}_{1 \mathrm{c}}<7 \%\right)$, and 10 $(41.67 \%)$ were affected by cerebral stroke. These patients had a total of 24 PrUs, of which 12 (50\%) were located in the sacral region, 9 (37.5\%) on the ischial tuberosity, and $3(12.5 \%)$ on the trochanter. Thirteen PrUs (54.17\%) were Stage III, and 11 (45.83\%) were Stage II. Their average duration was 2.81 months (range, 1-12 months), but most of them ( $n=18 ; 75 \%)$ developed less than 3 months before the study commenced. Five patients $(20.83 \%)$ had more than 1 PrU, of which the largest was monitored for healing.

\section{Primary Outcomes}

At week 1 of treatment, the PAR in the ES group was statistically significantly greater than that in the control group (35\% $\pm 30.5 \%$ compared with $17.07 \% \pm 34.13 \%$ in the control group; $P$ $=.032)$. The ES group maintained its advantage over the control group for the next 2 weeks (Figure 2). At week 4 of treatment, PAR4 was greater in the ES group (mean \pm SD, $71.64 \pm 33.74 \%$ ) than in the control group $(44.21 \pm 48.58 \%)$, but it was not statistically significant $(P=.064)$. In the next 2 weeks, wounds healed in both groups but at different paces. As a result, PAR6 was significantly greater in the ES group (mean \pm SD, $80.31 \pm 29.02 \%$ ) than in the control group (mean \pm SD, $54.65 \pm 42.65 \%$ ) at $P=.046$ (Figure 2).

\section{Secondary Outcomes}

The GF calculated for the ES group was significantly greater ( $0.95 \pm 0.5$ compared with $0.57 \pm 0.52$ in the control group; $\mathrm{P}$ $=.015)$ (Table 3).

In the ES group, the largest decreases in WSA were observed at weeks 1,2 , and 3 , by $35 \%, 32.78 \%$, and $45 \%$, respectively. In 
the control group, the rates were $17.07 \%, 12.78 \%$, and $20.32 \%$, respectively. At weeks 1 and 2, the differences were statistically significant and always in favor of the ES group $(P=.032, P=.044)$ (Figure 3).

The ES group had higher percentages of Stage II and III PrUs that closed (respectively, 9 of 11 [45\%] and 3 of 14 [17.65\%]) than the control group (6 of 11 [35.29\%] and 1 of 13 [6.25\%]), but the differences were not statistically significant (at $P=.74$ and $P=.6$ ) (Table 3).

Pressure ulcers did not increase in size in any of the patients treated with ES, whereas in the control group, 2 Stage III PrUs were larger relative to the baseline $(P=.22)$ (Table 3 ).

\section{Discussion}

The results of this clinical trial confirmed the research hypothesis that HVMPC accelerates the healing of Stage II through III PrUs. Ulcers managed with HVMPC in addition to SWC decreased statistically significantly more than those in the control group (SWC alone). In all patients, WSA decreased the fastest in the first 4 weeks of treatment. In weeks 5 and 6, the surface area of PrUs decreased at a slower rate. The PAR was significantly greater in the ES group than in the control group in all weeks but week 4 . The GF showed that regardless of their shape PrUs treated with a combination of SWC and HVMPC were decreasing significantly faster than were those receiving SWC alone. Unlike the ES group, where not a single PrU increased in size, in the control group, 2 Stage III PrUs were larger than at baseline. These results are consistent with the results obtained by other researchers who treated PrUs with HVMPC. $21,22,25-27$

Study patients received a diagnosis of Stage II (44.9\%) and III PrUs (55.1\%). Other investigators applied HVMPC to treat Stage II, III, and IV PrUs in spinal cord-injured patients, $\underline{21,25}$ older adult patients, 20,27 and patients immobilized for long periods owing to orthopedic injury. $\underline{26}$ This study, as well as other studies, $\underline{21,25-27}$ confirms that HVMPC can be effectively applied to treat PrUs.

Given that patients in this study had comorbid diseases that could stimulate the development of new PrUs or interfere with the healing of the existing ones, it was not expected that all their wounds would close over the 6 weeks of intervention. Accordingly, the 
percentage decrease in WSA relative to its baseline measurement (PAR) was taken as the primary research outcome. Special attention was given to PAR4 and PAR6. Percentage area reduction after 4 weeks is reported by many authors of clinical trials, $\underline{20-27}$ and the authors of the reviews of clinical studies $\frac{5,43}{}$ and epidemiological studies $^{44}$ consider it a predictor of PrU healing within 12 to 20 weeks. Percentage area reduction after 6 weeks was calculated to establish the degree of wound healing that could be achieved by applying cathodal HVMPC for 6 weeks.

In 15 randomized controlled trials analyzed by Koel and Houghton, $\underline{5} 4$ weeks of ES with monophasic electric current decreased Stage II-IV PrUs by $37.02 \%$ to $69.21 \%$, but in the control groups (SWC alone or SWC plus sham ES), the decrease ranged from $6.77 \%$ to $44.04 \%$. In this study, Stage II and III PrUs treated with HVMPC were smaller at week 4 by an average of $71.64 \%$ versus $44.21 \%$ in the control group, so these results are comparable with the results reported by Koel and Houghton. $\underline{5}$

Having analyzed retrospectively the effects of topical wound care on 306 VLUs and 241 DFUs, Cardinal 44 found PAR4 to predict the probability of wound closure in 12 weeks. For PAR $4=37.7 \%$, the positive predictive value for complete closure was $70.6 \%$, and the likelihood ratio was 6.15, meaning that the odds of total closure in 12 weeks were 6.15 times greater for wounds with PAR4 of at least $37.7 \%$ than for wounds with smaller PAR4. Considering Cardinal's 44 results, PAR4 of $71.64 \%$ obtained in this study for the ES group allows the authors to predict that PrUs would have closed in 12 weeks.

In this trial, at week 6 of treatment, the baseline area of Stage II and III PrUs in the ES group was smaller by $80.31 \%$. The results of other authors who also used HVMPC were very similar. Six weeks of HVMPC intervention in Franek et al. $\underline{26}$ and Polak et al. $\underline{27}$ studies on 26 Stage II and III PrUs $\underline{25}$ and 10 Stage II and III PrUs ${ }^{27}$ resulted in a PAR of $88.9 \%$ and $92.67 \%$, respectively. In Kloth and Feedar's study, $\underline{20} 9$ Stage IV PrUs healed completely during 7.3 weeks. Griffin et al. $\underline{21}$ recorded an $80 \%$ decrease in Stage II through IV PrUs after 20 successive days of treatment. Houghton et al. $\underline{25}$ who applied HVMPC to Stage II through IV PrUs, recorded that they were smaller in size by $70.0 \%$ at week 12 . 
Wound closure is another important surrogate endpoint in clinical trials indicated in reviews. $\stackrel{43}{ }$ The patients treated in this study did not stay in the care facilities long enough for the authors to observe them until all wounds closed. However, 6 weeks was sufficient for 9 of 11 Stage II PrUs (45\%) and 3 of 14 Stage III PrUs $(17.65 \%)$ treated with HVMPC + SWC to close. These observations suggest that HVMPC must be applied to older adult patients longer than 6 weeks for Stage II and III PrUs to close. Houghton et al. .25 noted that 12 weeks of HVMPC + SWC therapy caused all Stage II PrUs to close, but only 5 of 15 Stage III through IV PrUs (30\%). The authors concluded that 12 weeks of intervention with HVMPC + SWC was sufficient for Stage II PrUs to close, but in the case of more severe PrUs, longer application of ES combined with SWC might be necessary to achieve the same result. The study of Houghton et al. 25 does not provide an indication of how long ES should be applied for Stage III and IV PrUs to close, as the study was not long enough.

\section{Methodology of ES with HVMPC}

The HVMPC treatment protocol used in this study was similar to that used by other authors. $\frac{20-27}{}$ In all cases, the sterilized treatment electrode was placed on the wound, and the return electrode was attached to intact periwound skin approximately 15 to $20 \mathrm{~cm}$ from the wound edge. Both electrodes were separated from tissue by sterile gauze pads moistened with physiological saline. These measures maintained a moist wound environment and enhanced the flow of electric signal through the wound.

The available literature does not indicate what parameters make electric current particularly useful in treating different types of soft tissue wounds, but HVMPC in the voltage range from 100 to 150 $V$ that the authors of this study as well as other authors used to treat PrUs, $, 20,21,25-27$ VLUs, $, 22,24$ and DFUs $\underline{23}$ has been demonstrated to be effective. The amperage that was selected in this study $(0.24 \mathrm{~A})$ following other research protocols ${ }^{20-27}$ caused only sensory sensations in the patients, without evoking motor responses from the muscles. As in other studies, $\underline{23-30}$ the study used the HVMPC twin-peaked monophasic pulses of 154 microseconds and a frequency of 100 pps.

The authors of most studies involving HVMPC applied it to PrUs for 45 to 60 minutes, once a day, 5 to 7 days a week, so the total duration of ES ranged from 3.75 to 7 hours per week. $20-22,24,26,27$ The 
treatment sessions in this study were similar in duration: 50 minutes per day, 5 days per week, resulting in a total treatment time per week of 4.16 hours.

Reports from trials indicate that wound healing can be enhanced by several current waveforms, but Kloth $\underline{49}$ maintains that it is the electrical charge energy (charge quantity delivered to the wound) that determines the dosage that is the best to promote wound healing. According to Kloth's review of clinical studies, $\underline{49}$ ESs with LVMPC and HVMPC using an electrical charge of 250 to 500 $\mu \mathrm{C} /$ second can effectively advance the healing of chronic wounds. Some authors of clinical studies have not stated the value of the electrical charge they used. They set the charge at the sensory level below muscle contraction (visible or palpable) by asking the patients about their sensations. In this study, an electrical charge of 250 $\mu \mathrm{C} /$ second was adopted, the smallest of those recommended for wound treatment, because the patients were unable to describe how they felt the current. Because of the characteristics of electrical impulses, amperage had to be set to $0.24 \mathrm{~A}$ so that an electrical charge of $250 \mu \mathrm{C} /$ second could be obtained. In the pretrial tests, an amperage of $0.24 \mathrm{~A}$ was well tolerated by healthy patients, but larger dosages made some complain.

The application of cathodal stimulation in this study is supported by evidence from preclinical studies $\frac{36-40}{3}$ and has previously been reported by authors treating pressure ${ }^{22}$ and VLUs. ${ }^{24}$ Based on a review of the results of preclinical and clinical studies, Kloth and Zhao ${ }^{30}$ recommend using cathodal stimulation to improve the healing of noninfected wounds as long as regular wound measurements, increased granulation, and decreased exudation indicate that wound healing is steadily progressing. When wound measurements show that healing is not progressing or is regressing, polarity should be changed to positive and maintained as long as healing progress continues. If healing progress is observed to stop, polarity should be changed again and maintained for 7 to 14 treatments as long as healing progress is being made. In this study, cathodal HVMPC considerably decreased the WSA of PrUs in the first 3 weeks of treatment, by $35 \%$, $32.78 \%$, and $45.68 \%$, respectively (in the same period, healing rates in the control group were $17.07 \%, 12.78 \%$, and $20.32 \%$ a week). In the next weeks of cathodal stimulation, WSA continued to decrease,

Advances in Skin \& Wound Care, Vol 29, No. 10 (October 2016): pg. 447-459. DOI. This article is (C) Wolters Kluwer Health, Inc. and permission has been granted for this version to appear in e-Publications@Marquette. Wolters Kluwer Health, Inc. does not grant permission for this article to be further copied/distributed or hosted elsewhere without the express permission from Wolters Kluwer Health, Inc. 
although at a slower rate than in the early stage of treatment. This study does not answer the question about whether switching cathodal stimulation to anodal after 3 weeks would have enabled PrUs to heal as fast. Further clinical research seems necessary to obtain more information on this matter.

The groups of patients in this study were similar at the baseline regarding the key determinants of wound healing, such as age, wound duration, severity, and initial size. The groups consisted of older adult patients (most of whom were $>80$ years old) at high risk of PrU development, who had many comorbid conditions, such as systemic atherosclerosis, diabetes, protein deficit, hemoglobin deficit, lymphocytes deficit, and so on. Notwithstanding these unfavorable circumstances, the applied treatment proved effective. Patients receiving $\mathrm{ES}$ participated also in an interdisciplinary wound management program as recommended by the best practice guidelines on PrU treatment. 1,2

\section{Adverse Effects}

Neither in this study nor in the trials conducted by other investigators has HVMPC been found to have adverse effects.

\section{Study Limitations}

Because this study focused on patients with Stage II and III PrUs, the results do not predict the outcomes should cathodal HVMPC be used to treat Stage IV PrUs.

The 6-week treatment program (determined by average length of patient stay in the facility) was not long enough for all PrUs to heal. Consequently, it is not possible to conclude how long HVMPC should be applied for Stage II and III PrUs to close. Results enabling the evaluation of the long-term efficacy of PrU treatment are not presented for several reasons; primarily, after the trial ended some patients were discharged and returned to their homes or were transferred to other wards to be treated for concomitant diseases.

The PrU prevention and treatment program was designed for both groups based on the same best practice recommendations, $\underline{2,48}$ but particular solutions were adapted to meet the needs of individual patients. This customization may have contributed to differences in PrU healing between groups. 
NOT THE PUBLISHED VERSION; this is the author's final, peer-reviewed manuscript. The published version may be accessed by following the link in the citation at the bottom of the page.

\section{Conclusions}

This research has shown that HVMPC (154 microseconds, 100 pps, $100 \mathrm{~V}, 250 \mu \mathrm{C} /$ second) applied at a sensory level (50 minutes a day, 5 times a week) using the cathode as the treatment electrode is particularly effective in treating Stage II and III PrUs. This type of ES reduced the surface area of Stage II and III PrUs and accelerated their healing.

The results of the study are consistent with those obtained by other researchers who have found HVMPC to improve the healing of chronic wounds, including PrUs.

\section{Suggestions for Further Research}

Further RCTs are necessary to establish the efficacy of anodal and cathodal HVMPC applied independently and consecutively, as well as to determine the optimal parameters of this electric field signal.

\section{References}

${ }^{1}$ National Pressure Ulcer Advisory Panel, European Pressure Advisory Panel and Pan Pacific Pressure Injury Alliance. Prevention and Treatment of Pressure Ulcers: Clinical Practice Guideline. Haesler E, ed. Perth, Australia: Cambridge Media; 2014.

${ }^{2}$ Keast DH, Parslow N, Houghton PE, et al. Best practice recommendations for prevention and treatment of pressure ulcers: update 2006. Adv Skin Wound Care 2007;20:447-60.

${ }^{3}$ Smith ME, Totten A, Hickam DH, et al. Pressure ulcer treatment strategies. A systematic comparative effectiveness review. Ann Intern Med 2013;159:39-50.

${ }^{4}$ Thakral G, LaFontaine J, Najafi B, et al. Electrical stimulation to accelerate wound healing. Diabet Foot Ankle 2013;4.

${ }^{5}$ Koel G, Houghton P. Electrostimulation: current status, strength of evidence guidelines, and meta-analysis. Adv Wound Care 2014;3:118-26.

${ }^{6}$ Wood J, Evans P, Schallreuter K, et al. A multicenter study on the use of pulsed low-intensity direct current for healing chronic stage II and stage III decubitus ulcers. Arch Dermatol 1993;129:999-1009.

${ }^{7}$ Stefanovska A, Vodovnik L, Benko H, et al. Treatment of chronic wounds by means of electric and electromagnetic fields. Part 2. Value of FES parameters for pressure sore treatment. Med Biol Eng Comput $1993 ; 31: 213-20$.

Advances in Skin \& Wound Care, Vol 29, No. 10 (October 2016): pg. 447-459. DOI. This article is (C) Wolters Kluwer Health, Inc. and permission has been granted for this version to appear in e-Publications@Marquette. Wolters Kluwer Health, Inc. does not grant permission for this article to be further copied/distributed or hosted elsewhere without the express permission from Wolters Kluwer Health, Inc. 
NOT THE PUBLISHED VERSION; this is the author's final, peer-reviewed manuscript. The published version may be

accessed by following the link in the citation at the bottom of the page.

${ }^{8}$ Adunsky A, Ohry A. Decubitus direct current treatment (DDCT) of pressure ulcers: results of a randomized, double-blinded placebo controlled study. Arch Gerontol Geriatr 2005;41:261-9.

${ }^{9}$ Hampton S, Collis F. Treating a pressure ulcer with bio-electric stimulation therapy. Br J Nurs 2006;15:S14-8.

${ }^{10}$ Ullah MO. A study to detect the efficacy of microcurrent electrical therapy on decubitus wound. J Med Sci 2007;7:1320-4.

${ }^{11}$ Karba $R$, Benko $H$, Savrin $R$, et al. Combination of occlusive dressing and electrical stimulation in pressure ulcer treatment. Med Sci Res 1995;23:671-3.

${ }^{12}$ Jercinovic $A$, Karba $R$, Vodovnik $L$, et al. Low frequency pulsed current and pressure ulcer healing. IEEE Trans Rehabil Eng 1994;2:225-33.

${ }^{13}$ Petrofsky J, Lawson D, Berk L, et al. Enhanced healing of diabetic foot ulcers using local heat and electrical stimulation for 30 min three times per week. J Diabetes 2010;2:41-6.

${ }^{14}$ Weiss DS, Eaglstein WH, Falanga V. Exogenous electric current can reduce the formation of hypertrophic scars. J Dermatol Surg Oncol $1989 ; 15: 1272-5$.

${ }^{15}$ Feedar JA, Kloth LC, Gentzkow GD. Chronic dermal ulcer healing enhanced with monophasic pulsed electrical stimulation. Phys Ther $1991 ; 71: 639-49$.

${ }^{16}$ Gentzkow GD, Pollack SV, Kloth LC, et al. Improved healing of pressure ulcers using Dermapulse, a new electrical stimulation device. Wounds $1991 ; 3: 158-70$.

${ }^{17}$ Gentzkow GD, Alon G, Taler GA, et al. Healing of refractory stage III and IV pressure ulcers by a new electrical stimulation device. Wounds 1993;5:160-72.

18Junger $M$, Zuder $D$, Steins $A$, et al. Treatment of venous ulcers with low frequency pulsed current (Dermapulse): effects on cutaneous microcirculation. Hautartz 1997;48:879-903.

${ }^{19}$ Adegoke B, Badmos K. Acceleration of pressure ulcer healing in spinal cord injured patients using interrupted direct current. Afr J Med Sci 2001;30:195-7.

${ }^{20}$ Kloth LC, Feedar JA. Acceleration of wound healing with high voltage monophasic, pulsed current. Phys Ther 1988;68:503-8.

${ }^{21}$ Griffin JW, Tooms RE, Mendius RA, et al. Efficacy of high voltage pulsed current for healing of pressure ulcers in patients with spinal cord injury. Phys Ther 1991;71:433-42.

Advances in Skin \& Wound Care, Vol 29, No. 10 (October 2016): pg. 447-459. DOI. This article is (C) Wolters Kluwer Health, Inc. and permission has been granted for this version to appear in e-Publications@Marquette. Wolters Kluwer Health, Inc. does not grant permission for this article to be further copied/distributed or hosted elsewhere without the express permission from Wolters Kluwer Health, Inc. 
NOT THE PUBLISHED VERSION; this is the author's final, peer-reviewed manuscript. The published version may be accessed by following the link in the citation at the bottom of the page.

${ }^{22}$ Franek A, Polak A, Kucharzewski M. Modern application of high voltage for enhanced healing of venous crural ulceration. Med Eng Phys $2000 ; 22: 647-55$

${ }^{23}$ Peters EJ, Lavery LA, Armstrong DG, et al. Electric stimulation as an adjunct to heal diabetic foot ulcers: a randomized clinical trial. Arch Phys Med Rehabil 2001;82:721-5.

${ }^{24}$ Houghton PE, Kincaid CB, Lovell M, et al. Effect of electrical stimulation on chronic leg ulcer size and appearance. Phys Ther 2003;831:17-28.

${ }^{25}$ Houghton $\mathrm{PE}$, Campbell $\mathrm{KE}$, Fraser $\mathrm{CH}$, et al. Electrical stimulation therapy increases rate of healing of pressure ulcers in community-dwelling people with spinal cord injury. Arch Phys Med Rehabil 2010;91:66978.

${ }^{26}$ Franek $A$, Kostur $R$, Polak $A$, et al. Using high voltage electrical stimulation in the treatment of recalcitrant pressure ulcers: results of a randomized, controlled trial. Ostomy Wound Manage 2012;58:30-44.

${ }^{27}$ Polak A, Walczak A, Taradaj J, et al. High-voltage pulsed current in pressure ulcer healing: results of a randomized, controlled trialpreliminary study. Leczenie Ran 2013;10:13-22.

${ }^{28}$ Houghton PE. Clinical trials involving biphasic pulsed current, microcurrent, and/or low-intensity direct current. Adv Wound Care 2014;3:166-83.

${ }^{29}$ Polak A, Franek A, Taradaj J. High-voltage pulsed current electrical stimulation in wound treatment. Adv Wound Care 2014;3:104-17.

${ }^{30} \mathrm{Kloth}$ LC, Zhao M. Endogenous and exogenous electrical fields for wound healing. In: McCulloch JM, Kloth LC, eds. Wound Healing. EvidenceBased Management. 4th ed. Philadelphia, PA: FA Davis Company; 2010:450-513.

${ }^{31}$ Orida N, Feldman J. Directional protrusive pseudopodial activity and motility in macrophages induced by extra-cellular electric fields. Cell Motil $1982 ; 2: 243-55$.

${ }^{32}$ Fukushima K, Senda N, Inui $\mathrm{H}$, et al. Studies on galvanotaxis of leukocytes. Med J Osaka Univ 1953;4(2-3):195-208.

${ }^{33}$ Eberhardt A, Szczypiorski P, Korytowski G. Effect of transcutaneous electrostimulation on the cell composition of skin exudates. Acta Physiol Pol 1986;37:41-6.

${ }^{34}$ Talebi G, Torkaman G, Firoozabadi M, et al. Effect of anodal and cathodal microamperage direct current electrical stimulation on injury potential and wound size in guinea pigs. J Rehabil Res Dev 2008;45:153-60.

Advances in Skin \& Wound Care, Vol 29, No. 10 (October 2016): pg. 447-459. DOI. This article is (C) Wolters Kluwer Health, Inc. and permission has been granted for this version to appear in e-Publications@Marquette. Wolters Kluwer Health, Inc. does not grant permission for this article to be further copied/distributed or hosted elsewhere without the express permission from Wolters Kluwer Health, Inc. 
NOT THE PUBLISHED VERSION; this is the author's final, peer-reviewed manuscript. The published version may be accessed by following the link in the citation at the bottom of the page.

${ }^{35}$ Borba GC, Hochman B, Liebano RE, et al. Does preoperative electrical stimulation of skin alter the healing process? J Surg Res 2011;166:324-9.

${ }^{36}$ Nishmura KY, Isseroff RR, Nuccitelli R. Human keratinocytes migrate to the negative pole in direct current electric fields comparable to those measured in mammalian wounds. J Cell Sci 1996;109:199-207.

${ }^{37}$ Erickson CA, Nuccitelli R. Embryonic fibroblast motility and orientation can be influenced by physiological electric fields. J Cell Biol 1984;98:296307.

${ }^{38}$ Young $W$, Onuma EK, Hui SW. Response of $\mathrm{C} 3 \mathrm{H} / 10 \mathrm{~T} 1 / 2$ fibroblasts to an external steady electric field stimulation. Exp Cell Res 1984;155:92104.

${ }^{39}$ Zhao M, Song B, Pu J, et al. Electrical signals control wound healing through phosphatidylinositol-3-OH kinase-gamma and PTEN. Nature 2006;442:457-60.

${ }^{40}$ Bourguignon GJ, Jy W, Bourguignon LY. Electric stimulation of human fibroblasts causes an increase in $\mathrm{Ca}^{2+}$ influx and the exposure of additional insulin receptors. J Cell Physiol 1989;140:379-85.

${ }^{41}$ Bourguignon GJ, Bourguignon LY. Electric stimulation of protein and DNA synthesis in human fibroblasts. FASEB J 1987;1:398-402.

${ }^{42}$ Asadi MR, Torkaman G, Hedayati M. Effect of sensory and motor electrical stimulation in vascular endothelial growth factor expression of muscle and skin in full-thickness wound. J Rehabil Res Dev 2011;48:195202.

${ }^{43}$ Gottrup F, Apelqvist J, Price P. Outcomes in controlled and comparative studies on non-healing wounds: recommendations to improve the quality of evidence in wound management. $J$ Wound Care 2010;19:239-68.

${ }^{44}$ Cardinal M, Eisenbud DE, Philips $T$, et al. Early healing rates and wound area measurements are reliable predictors of later complete wound closure. Wound Repair Regen 2008;16:19-22.

${ }^{45} \mathrm{Gilman} \mathrm{TH}$. Parameter for measurement of wound closure. Wounds $1990 ; 2(3): 95-101$.

${ }^{46} \mathrm{Gilman} \mathrm{TH}$. Comparing healing rates across studies is the vision, but first, a correct equation please! Ostomy Wound Manage 1995;41:6-7.

${ }^{47}$ Kondrup J, Rasmussen $\mathrm{HH}$, Hamberg $\mathrm{O}$, et al. Nutritional risk screening (NRS 2002): a new method based on an analysis of controlled clinical trials. Clin Nutr 2003;22:321-6.

Advances in Skin \& Wound Care, Vol 29, No. 10 (October 2016): pg. 447-459. DOI. This article is (C) Wolters Kluwer Health, Inc. and permission has been granted for this version to appear in e-Publications@Marquette. Wolters Kluwer Health, Inc. does not grant permission for this article to be further copied/distributed or hosted elsewhere without the express permission from Wolters Kluwer Health, Inc. 
NOT THE PUBLISHED VERSION; this is the author's final, peer-reviewed manuscript. The published version may be accessed by following the link in the citation at the bottom of the page.

${ }^{48}$ Szewczyk M, Sopata M, Jawien A, et al. Zalecenia profilaktyki i leczenia odlezyn. Leczenie Ran 2010;7:79-106.

${ }^{49} \mathrm{Kl}$ loth LC. Wound healing with conductive electrical stimulation-it's the dosage that counts. J Wound Technol 2009;6:30-7.

The authors have disclosed that the high-voltage monophasic pulsed current electrical stimulator studied in this article is the US Food and Drug Administration's unlabeled investigational device Intelect Advanced Combo unit (Model 2771; Chattanooga Group, Vista, California).

Acknowledgments: The authors thank the physical therapists, physicians, and nurses who helped conduct the research, particularly Lidia Adamczyk, MSc; Aldona Augustak, MSc; and Dr Malgorzata Engelmann.

Advances in Skin \& Wound Care, Vol 29, No. 10 (October 2016): pg. 447-459. DOI. This article is (C) Wolters Kluwer Health, Inc. and permission has been granted for this version to appear in e-Publications@Marquette. Wolters Kluwer Health, Inc. does not grant permission for this article to be further copied/distributed or hosted elsewhere without the express permission from Wolters Kluwer Health, Inc. 
NOT THE PUBLISHED VERSION; this is the author's final, peer-reviewed manuscript. The published version may be accessed by following the link in the citation at the bottom of the page.

\section{Image Gallery}

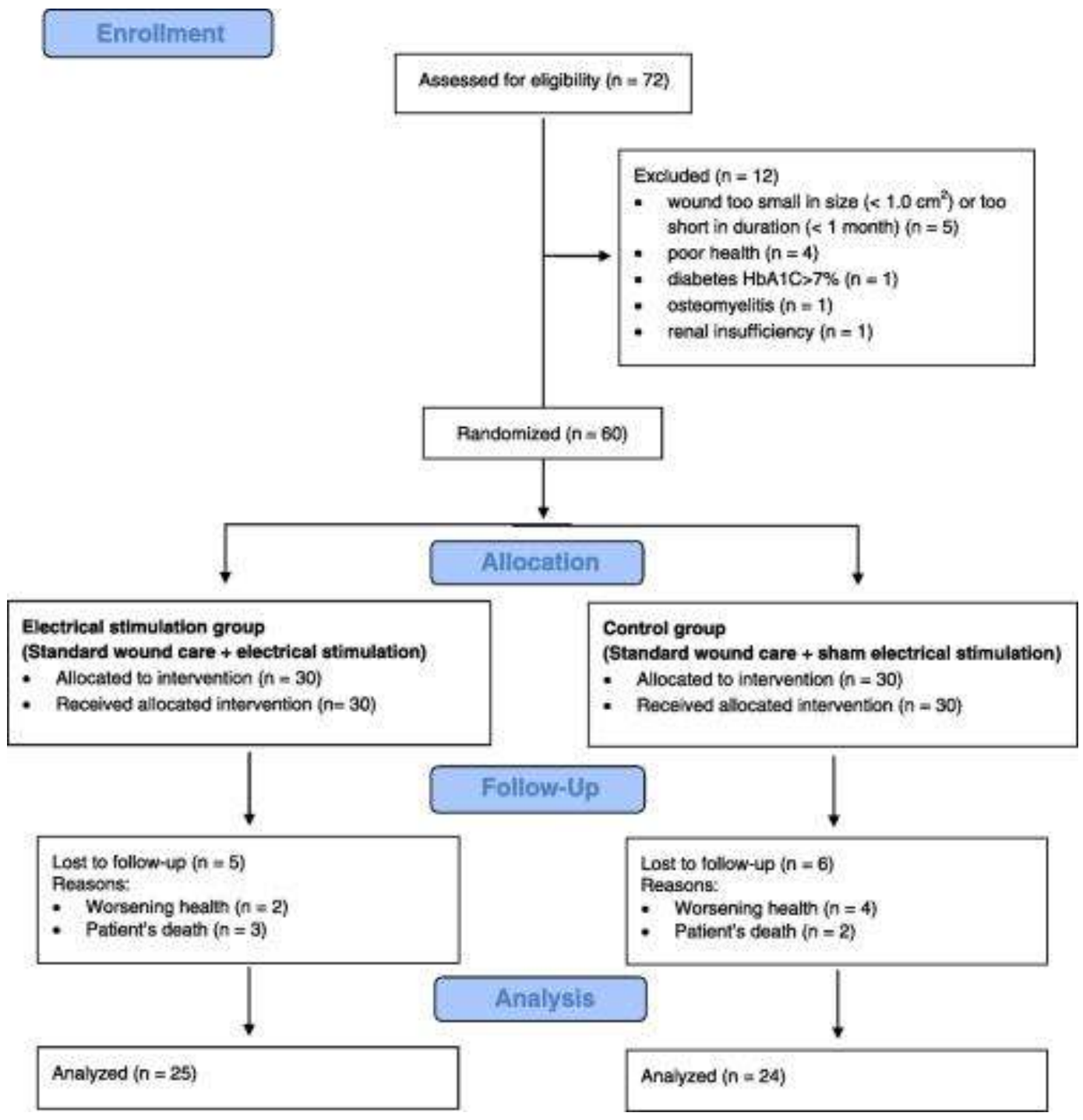

Figure 1. Flow Diagram of The Study Process

Advances in Skin \& Wound Care, Vol 29, No. 10 (October 2016): pg. 447-459. DOI. This article is (C) Wolters Kluwer Health, Inc. and permission has been granted for this version to appear in e-Publications@Marquette. Wolters Kluwer Health, Inc. does not grant permission for this article to be further copied/distributed or hosted elsewhere without the express permission from Wolters Kluwer Health, Inc. 
NOT THE PUBLISHED VERSION; this is the author's final, peer-reviewed manuscript. The published version may be accessed by following the link in the citation at the bottom of the page.

Table 1. Baseline Patient And Wound Characteristics $(N=49)$

\begin{tabular}{|c|c|c|c|}
\hline Variable & ES Group (SWC + HVMPC) & Control Group (SWC + Sham HVMPC) & Level of Significanoe \\
\hline Sample sins, n9, of patienss & 25 & 24 & \\
\hline coodsr: semabimake ns, of pationss & $19.75 \% 56$ (24) & 13 (759) 6 (25\%) & $P=75^{3}$ \\
\hline Ags, men = Samin-mavimasan, y & $79.92=8501609089$ & $7633=1274.60-96 / 81$ & $P=53^{\circ}$. \\
\hline $\begin{array}{l}\text { No. Bhi of patiects by ags bend } \\
60-69 \text { y } 70-79 \text { y. } 80 \text { y }\end{array}$ & 3 3125y) ,285yt5 (60\%) & 6 (255)7 (25:4)12 (5094) & $P=.29^{N} \vee R=1^{2} / P=57$ \\
\hline BM: BM $\triangle 30 \mathrm{~kg} / \mathrm{m}^{2} / \mathrm{BW}<19 \mathrm{~kg} / \mathrm{m}^{2}$, no of pations & $280 \% 44(965)$ & $31125 \% \sqrt{2} 1833 \times 4$ & $P=6 \pi^{2} / P=67^{\circ}$ \\
\hline Unatie to shanje pastion uncidad no $\alpha$ patents & 2018059 & $19(79.173)$ & $P=\pi^{3}$ \\
\hline 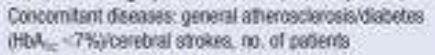 & 16 (648:41 i444) (36\%) & 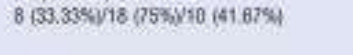 & $P=56^{\circ} / P=56 \%=77$ \\
\hline No. ise) of patants wot maltipe prus & $6(24 \%)$ & $5(20) 838\}$ & $P=1^{*}$ \\
\hline No. this $U$ pateants wht recusent Pris & If isese) & $12(50 \%)$ & $P=1^{*}$ \\
\hline 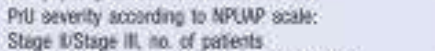 & $11(406) / 46 / 56 \%)$ & 1145.80 ray 13 (54.17s & $P_{\alpha} .7 g^{2} P=.79^{4}$ \\
\hline 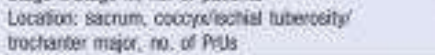 & $13152 \% 60$ (32\%)/4 त6\%) & 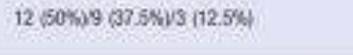 & $P=79 M P-7 D F=1 *$ \\
\hline
\end{tabular}

Table 2. Baseline Characteristics Of Pressure Ulcers $(N=49)$

\begin{tabular}{|c|c|c|c|}
\hline Vsriabie & ES Group (25 Patients) & Control Group (24 Patients) & Level of Significance \\
\hline WSh of Prts, mean = SOVmis mow medan $\mathrm{cm}^{2}$ & $10.55=10.5717 .20-36.34,5.58$ & $9.71 \div 6.702202 .32 .434 .73$ & $\hat{p}=49^{2}$ \\
\hline Wh. of Pelis by WSE $1.0-5 \mathrm{~cm}^{2} / 5.1-10 \mathrm{~cm}^{2} / 10 \mathrm{~cm}^{2}$ & 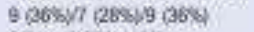 & $709.1734)(33,33 \% 1 / 9$, $37.5 \%)$ & $P=.7 Q^{b}>P=. x^{2} / P=.79^{\circ}$ \\
\hline Duraton of Prik mean 1 SQimin-mex/nedar, ao & $2.54=20054-10 / 2$ & $281+2.671-122$ & $\theta=22$ \\
\hline Nb. of prus by duntion: 13 mo/3.1-6 mokb.1-12 mo & 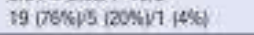 & 18 (75):4 (16.6rs\$2 18.335$)$ & $P=78^{3} \%=.1^{b} \%=.61^{b}$ \\
\hline
\end{tabular}

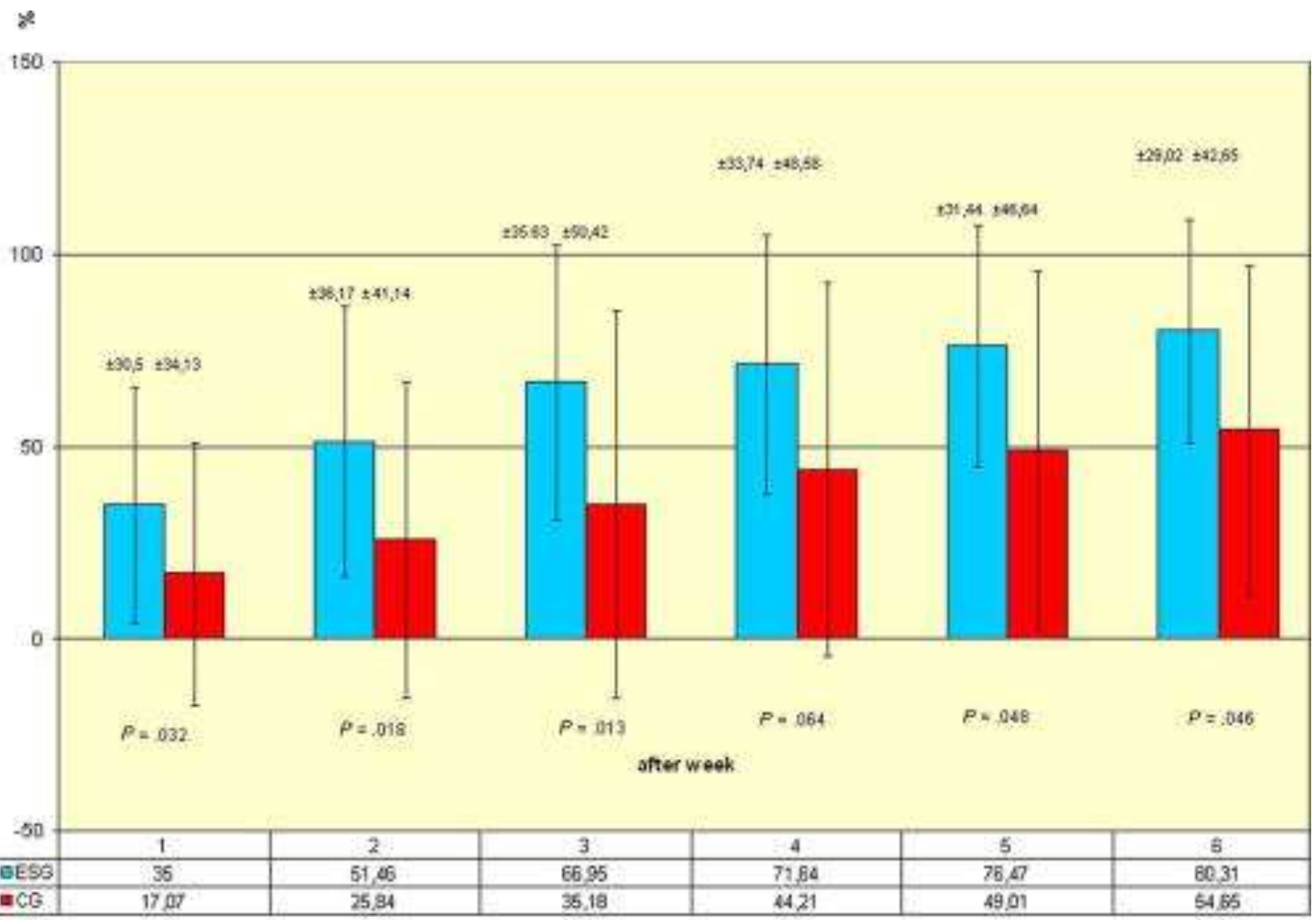

Abbreviations: CG, control group; ESG, electrical stimulation group.

Figure 2. Cumulative Percentage Change In Wound Surface Area Calculated After Each Week Of Treatment

Advances in Skin \& Wound Care, Vol 29, No. 10 (October 2016): pg. 447-459. DOI. This article is (C) Wolters Kluwer Health, Inc. and permission has been granted for this version to appear in e-Publications@Marquette. Wolters Kluwer Health, Inc. does not grant permission for this article to be further copied/distributed or hosted elsewhere without the express permission from Wolters Kluwer Health, Inc. 
NOT THE PUBLISHED VERSION; this is the author's final, peer-reviewed manuscript. The published version may be accessed by following the link in the citation at the bottom of the page.

Table 3. Comparison Of Wound Outcomes Between Groups ( $N=49)$

\begin{tabular}{|c|c|c|c|c|c|}
\hline & \multicolumn{2}{|c|}{ ES Group (SWC + HVMPC) } & \multicolumn{2}{|c|}{$\begin{array}{l}\text { Control Group } \\
\text { (SWC + Sham BVMPC) }\end{array}$} & \multirow[b]{2}{*}{ Levet of Signifieance } \\
\hline & Ka of Prus & {$[B]+S D$} & 15o. of Pris & {$[x]=50$} & \\
\hline Eltess formula for Pros S SD & 25 & $0.96=0.5$ & 24 & $0.57 \geq 0.52$ & $P=015^{\circ}$ \\
\hline 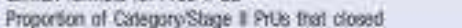 & i1 & $921-25 x$ & 11 & $611-35.20 \%$ & $P=74^{k}$ \\
\hline 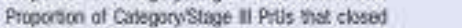 & 14 & $394-17.55 \%$ & 13 & $1 / 3=625$ & $p=5^{\circ}$ \\
\hline 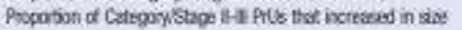 & 25 & $0025=0 \%$ & 24 & $224-6.936$ & $p=.22^{\prime \prime}$ \\
\hline
\end{tabular}

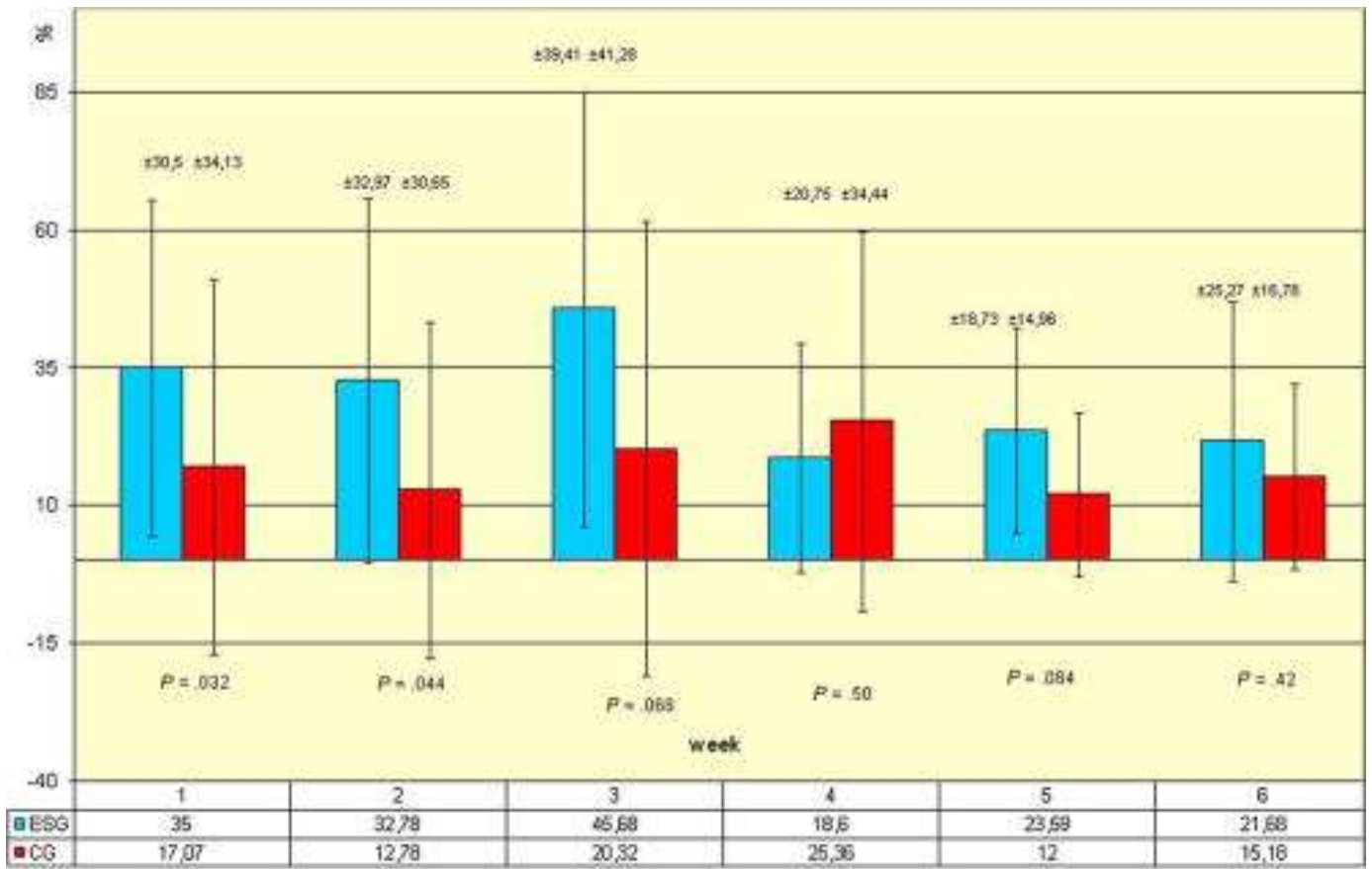

Abbreviations: $\mathrm{CG}$, control group; ESG, electrical stimulation group.

Figure 3. Percentage Change In Wound Surface Area Calculated For Each Week Of Treatment

Advances in Skin \& Wound Care, Vol 29, No. 10 (October 2016): pg. 447-459. DOI. This article is (C) Wolters Kluwer Health, Inc. and permission has been granted for this version to appear in e-Publications@Marquette. Wolters Kluwer Health, Inc. does not grant permission for this article to be further copied/distributed or hosted elsewhere without the express permission from Wolters Kluwer Health, Inc. 